\title{
Comparative Evaluation of Taper Preparation Variability of Three Different Niti Files- An In Vitro CBCT Study
}

\author{
Dr. Tirthankar Bhaumik, BDS (UNB, W.B.) \\ Post Graduate Student West Bengal University of Health Sciences, \\ Department of Conservative Dentistry \& Endodontics Guru Nanak Institute \\ of Dental Sciences and Research Panihati, Kolkata, West Bengal, India \\ Dr. Utpal Kumar Das, BDS (C.U.), MDS (BHU) \\ Professor and Head of the Department Department of Conservative Dentistry \\ \& Endodontics Guru Nanak Institute of Dental Sciences and Research \\ Panihati, Kolkata, West Bengal, India
}

Dr. Kaushik Dutta, BDS(WBUHS) MDS(MJPRU)

Senior Lecturer Department of Oral and Maxillofacial Radiology Guru

Nanak Institute of Dental Sciences and Research Panihati, Kolkata, West

Bengal, India

doi: 10.19044/esj.2016.v13n3p126 URL:http://dx.doi.org/10.19044/esj.2016.v13n3p126

\begin{abstract}
The ultimate goal of an endodontic treatment is to achieve the fluid tight seal particularly at the apex as well as in coronal aspect of the root canal system. This is mainly influenced by the cleaning and shaping of root canal system and it has been recognized as an important phase of endodontic therapy. Cleaning and shaping as well as obturation are best accomplished when the file taper claimed by the manufacturer is accurate and the taper of the canal following instrumentation corresponds to the taper of the file. Despite the most advanced technology in manufacturing of dental instruments, variations in endodontic file tapers still exist. Therefore the purpose of this study is to compare the taper variation in root canal preparations among the three different NiTi files using CBCT. Methods: 24 upper 1st molar tooth with mesiobuccal root curvature 15-30 degree were selected and divided into three groups. Mesiobuccal roots (MB1) of three groups were prepared by three different NiTi file system respectively up to size25 taper.06 and CBCT were done separately for each group. The diameter was measured at 1,3 , and orifice in $\mathrm{mm}$ and canal taper preparation was calculated using CBCT. Result: Of the 3 file systems, fell within the \pm .05 taper variability. All preparations demonstrated variability when compared to the nominal taper .06. Conclusion: Taper preparations of the
\end{abstract}


investigated size 25 taper .06 were favorable but different from the nominal taper.

Keywords: Comparative, Evaluation, In-vitro, Taper, NiTi, Study

\section{Introduction:}

The goal of endodontics has been set as to achieve an adequate fluid tight seal particularly at the apex and coronal aspect in order to prevent leakage (J. T. Lask and co-orkers,2006) which is great way dependent on Cleaning and shaping of the root canals. To best achieve this goal, the root canal preparation should develop a continuously tapering cone corresponding to the taper of the file. Taper of file is usually expressed as the amount the file diameter increases each millimeter along its working surface from the tip towards the file handle (Cohen's Pathways of the pulp,10th edition,p-233) and it was standardized by Ingle (J. I. Ingle,1961) Heuer (M. Heuer,1963), and others who developed international standards on size, taper, and performance of endodontic files (ISO specification 3630-1, "Dental rootcanal instruments: part 1-1992) Further revisions were made by the International Standards Organization (ISO) and stated the specification 101 of the American National Standards Institute/American Dental Association (ANSI/ADA) in the year 2001. Currently the ANSI/ADA specification 101 states the taper dimensional requirements for endodontic files of any taper and ISO 3630-1 serve as the standard to which endodontic file is compared.

Despite the most advanced technology in manufacturing of dental instruments, variations in endodontic file tapers still exist within allowable taper variation tolerance. (G.J.Dearing, 2005) According to the ANSI/ADA specification 101, the allowable taper variation tolerance, for any size file or root canal preparation (RCT), is \pm 0.05 . This means that if a manufacturer states that the nominal file taper is .06, the taper can vary between .01 and .11 and still fall within the current acceptable standards on taper; a large amount of variance might occur and still be within the standard.

Till today, there are very few studies have been conducted to analyze root canal preparation taper variability with NiTi rotary endodontic files to current standards though now a days nickel-titanium (NiTi) rotary instruments are the most popular and important part of the armamentarium for root canal treatment. Several metallurgical advancement took place since its discovery by W.F.Buehler (1960). M-Wire, CM Wire and R-phase NiTi are recent remarkable advancement, introduced with structural optimization of the NiTi wire blanks. Protaper Next(Dentsply,Maillefer), Hyflex CM(Coltene Whaledent) and Twisted file (SybronEndo) are made by Mwire, CM-Wire and R-Phase Niti respectively having distinct structural variation with different metallurgical configuration and mechanical 
properties. The purpose of this study was to compare the taper preparation variability among the Protaper Next, Hyflex CM and Twisted file system of size 25, .06 tapered NiTi rotary files.

\section{Materials and Methods}

A total of 24 extracted maxillary first molars with completely formed mesiobuccal root apices and mesiobuccal root curvatures ranging between 15-30 degrees (measured by Schneider's method) having no cracks or anomalies were collected and stored in $10 \%$ buffered formalin. Access cavity was prepared using a high-speed round carbide bur (Dentsply,

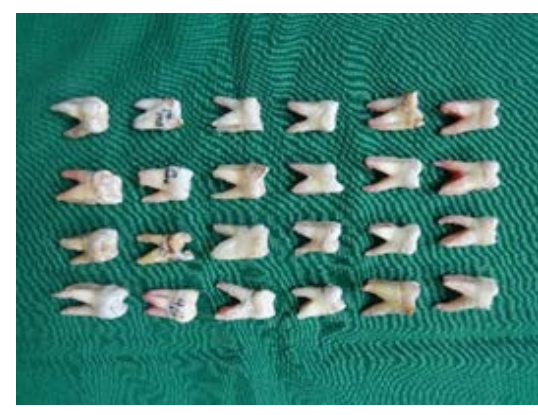
Maillefer) with water spray. A size $10 \mathrm{~K}$-file (Dentsply, Maillefer) was placed into the mesiobuccal canal (MB1) until it was visible at the apical foramen and the working length established $1 \mathrm{~mm}$ short of this length. If the apical diameter was larger than a $10 \mathrm{~K}$-file, the tooth was excluded from the study. The teeth were randomly divided into the three following groups- $\mathrm{Gr}$ A, Gr B, Gr C ( $(n=8)$. Teeth were embedded into the wax block maintaining the groups. Pre instrumentation CBCT was done (myRay digital imaging system) as a control. All MB1 root canals were instrumented to the working length with sizes 10 and $15 \mathrm{~K}$-files using a step-back technique. Canals that were larger than ISO size 15 were discarded.

After that Gr.A was prepared by Protaper-Next file system(X2, 6\% 25), Gr. B was prepared by Hyflex CM (6\% 25), Gr. C was prepared by Twisted file $(6 \% 25)$ according to the manufacturer's recommendations. All instrumented canals were irrigated by $2.5 \% \mathrm{NaOCl}$ and $17 \%$ EDTA solution. Teeth were re-embedded into the wax block maintaining their groups. Post instrumentation CBCT was done and seen by iRYS viewer version 5.6[Installation package: 5.6.0].

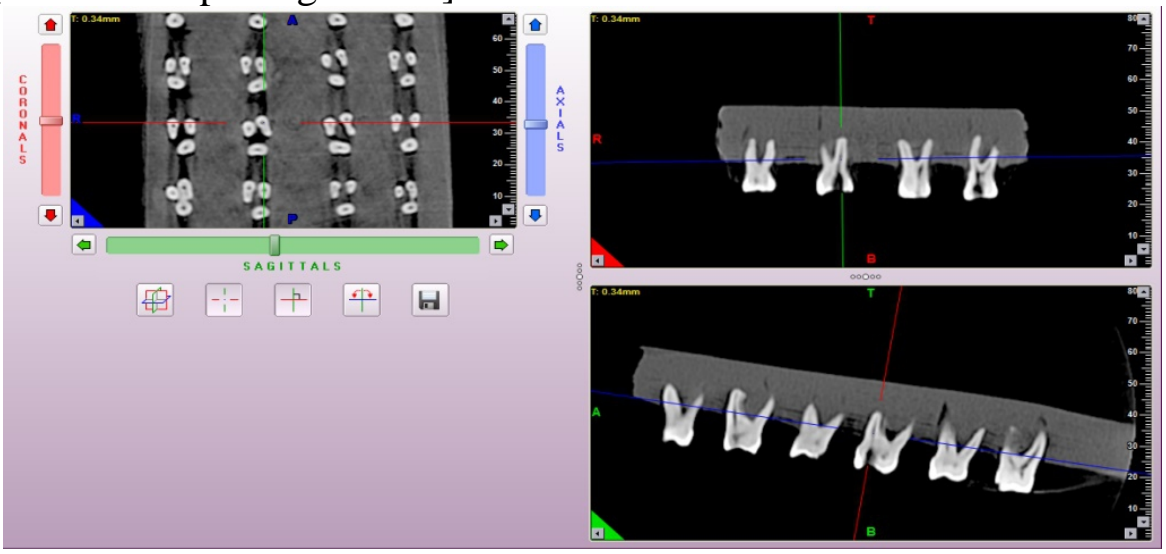


Three sections from each MB1 roots, and its level were measured from CBCT. The first two sections were at $1 \mathrm{~mm} \& 3 \mathrm{~mm}$ from the apical end of the root respectively. The 3rd section was at root canal orifice (D0). Taper (T1) was determined from the diameter at D3 and D0 of each root canal preparation using the equation: Taper $=$ D0 diameter - D3 Diameter $(\mathrm{mm}) /$ Distance between D0 and D3, where D0 and D3 are the shortest distance from the mesial edge to the distal edge of the instrumented canal. This equation was obtained from the ISO 3630-1 protocol for determining file taper with the measured diameter locations at D0 and D3.

According to the ProTaper Next manufacturer Both the X1 and X2 files have an increasing and decreasing percentage taper on a single file, Because of the variable taper of the ProTaper Next file, another taper (T2) measure was evaluated in the first $3 \mathrm{~mm}$ of each file preparation for all groups using the equation: Taper $=$ D3 diameter - D1 Diameter (mm)/Distance between D3 and D1.

Another taper (T3) was evaluated form the diameter of apex (D1) to root canal orifice (D0) using the equation: Taper $=$ D0 diameter - D1 Diameter (mm)/Distance between D0 and D1 i.e. overall taper preparation from apex to orifice.

\section{Results and statistical analysis}

The calculated taper file preparations are tabulated and variation from the nominal taper are calculated. The 3 system preparations fell within the ANSI/ADA specification 101 for taper variability of \pm .05 . Statistical Analyses were performed with help of Epi Info (TM) 3.5.3. EPI INFO is a trademark of the Centers for Disease Control and Prevention (CDC).

Descriptive statistical analyses were performed to calculate the means with corresponding standard errors (s.e.). Z test was used to test the calculated means with the specified mean. t-test was used to test the significant difference between means. $\mathrm{p}<0.05$ was taken to be statistically significant.

Comparison (\%):

\begin{tabular}{|c|c|c|c|}
\hline & T1\% (mean \pm s.e.) & T2\% (mean \pm s.e.) & T3\% (mean \pm s.e.) \\
\hline PTN $(\mathrm{n}=8)$ & $5.35 \pm 1.93$ & $7.50 \pm 1.64$ & $6.15 \pm 1.22$ \\
\hline HCM $(\mathrm{n}=8)$ & $3.22 \pm 1.61$ & $3.75 \pm 1.83$ & $3.52 \pm 1.19$ \\
\hline TF $(\mathrm{n}=8)$ & $4.18 \pm 1.28$ & $2.92 \pm 1.94$ & $3.71 \pm 0.86$ \\
\hline PTN Vs & $\mathrm{t}_{14}=2.39 ; \mathrm{p}=0.03^{*}$ & $\mathrm{t}_{14}=4.31 ; \mathrm{p}=$ & $\mathrm{t}_{14}=4.36 ; \mathrm{p}=0.0007^{*}$ \\
HCM & & $0.0007 *$ & $\mathrm{t}_{14}=4.62 ; \mathrm{p}=0.0004^{*}$ \\
\hline PTN Vs TF & $\mathrm{t}_{14}=1.42 ; \mathrm{p}=0.17$ & $\mathrm{t}_{14}=5.09 ; \mathrm{p}=$ & \\
& & $0.0002^{*}$ & $\mathrm{t}_{14}=0.36 ; \mathrm{p}=0.72$ \\
\hline HCM Vs TF & $\mathrm{t}_{14}=1.32 ; \mathrm{p}=0.21$ & $\mathrm{t}_{14}=0.88 ; \mathrm{p}=0.39$ & \\
\hline
\end{tabular}


Mean T1\% of PTN was significantly higher than that of HCM $(\mathrm{p}<0.01)$ but no significant difference was found between PTN and TF $(\mathrm{p}>0.05)$.

Mean taper (T2\%) of PTN was significantly higher than that of HCM and TF $(\mathrm{p}<0.01)$ but there was no significant difference in mean taper $(\mathrm{T} 2 \%)$ of HCM and TF ( $>>0.05)$.

Mean taper (T3\%) of PTN was significantly higher than that of HCM and TF $(\mathrm{p}<0.01)$ but there was no significant difference in mean taper (T3\%) of HCM and TF ( $>>0.05)$. below.

This variation of taper preparations are graphically represented

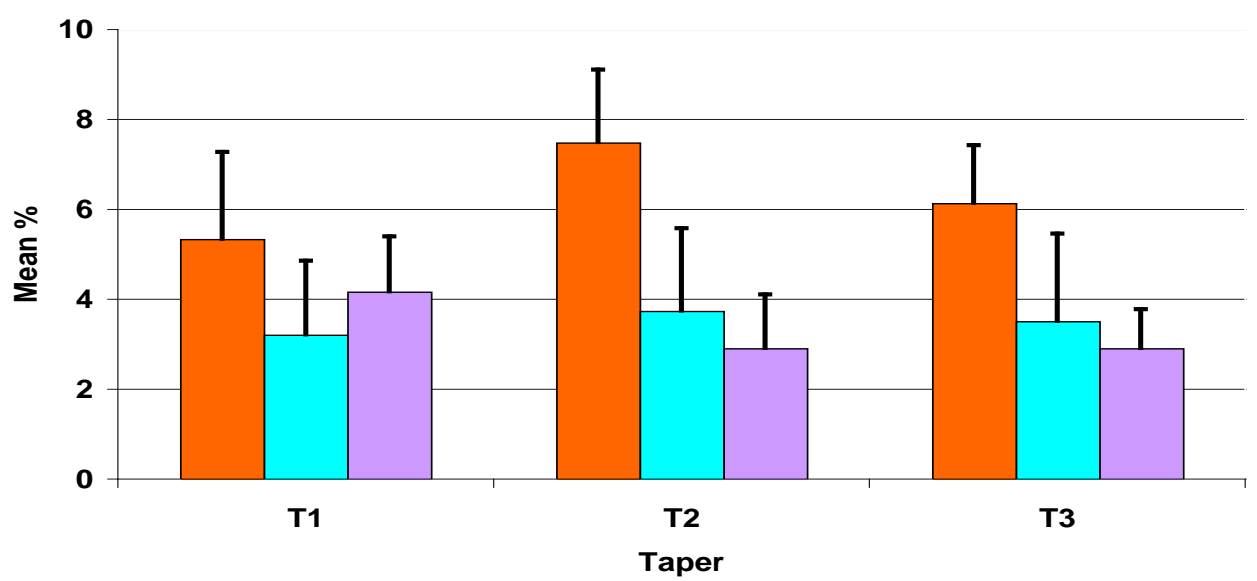

$\square$ PTN $\square$ HCM $\square$ TF

\begin{tabular}{|c|c|c|c|}
\hline & T1\% (mean \pm s.e.) & T2\% (mean \pm s.e.) & T3\% (mean \pm s.e.) \\
\hline PTN (n=8) & $5.35 \pm 1.93$ & $7.50 \pm 1.64$ & $6.15 \pm 1.22$ \\
\hline HCM (n=8) & $3.22 \pm 1.61$ & $3.75 \pm 1.83$ & $3.52 \pm 1.19$ \\
\hline TF $(\mathrm{n}=8)$ & $4.18 \pm 1.28$ & $2.92 \pm 1.94$ & $3.71 \pm 0.86$ \\
\hline PTN Vs & $\mathrm{Z}=0.94 ; \mathrm{p}=0.34$ & $\mathrm{Z}=2.56 ; \mathrm{p}=$ & $\mathrm{Z}=0.34 ; \mathrm{p}=0.73$ \\
$\begin{array}{c}\text { Normal Value } \\
(6 \%)\end{array}$ & & $0.0105^{*}$ & \\
\hline $\begin{array}{c}\text { HCM Vs } \\
\text { Normal Value } \\
(6 \%)\end{array}$ & $\mathrm{Z}=4.83 ; \mathrm{p}<0.0001^{*}$ & $\mathrm{Z}=3.44 ; \mathrm{p}<0.001^{*}$ & $\mathrm{Z}=5.83 ; \mathrm{p}<0.001^{*}$ \\
\hline $\begin{array}{c}\text { TF Vs } \\
\text { Normal Value } \\
(6 \%)\end{array}$ & $\mathrm{Z}=3.98 ; \mathrm{p}<0.0001^{*}$ & $\mathrm{Z}=4.44 ; \mathrm{p}<0.001^{*}$ & $\mathrm{Z}=7.45 ; \mathrm{p}<0.0001^{*}$ \\
\hline
\end{tabular}

Deviation from nominal taper are analyzed and tabulated above and clearly indicates that only T2\% of PTN was significantly higher than normal range $6 \%(p<0.01)$. All other values were significantly lower than normal 
range $6 \%(\mathrm{p}<0.01)$. No significant difference was found with normal range for T1 and T3 of PTN ( $>0.05)$.

So that it can be said that taper preparation by Protaper Next file system is better and nearer to claimed nominal taper than taper prepared by Hyflex CM and Twisted file system.

\section{Discussion}

Over the past two decades, nickel-titanium (NiTi) instruments have become an important part of the armamentarium for root canal treatment. They are increasingly used by generalists and specialists to facilitate the cleaning and shaping of root canals (Ya Shen et al, 2013). Root canal instrumentation with rotary $\mathrm{NiTi}$ files improves preparation quality, particularly in terms of reducing the occurrence of ledges, zips, and root canal transportation (Blum et al,2003). There are several methods introduced to evaluate the efficiency of the root canal instrumentation. Radiography is one of them and it can be done without physical intervention but it only provides a two-dimensional image and a cross-section of the root canal is impossible to observe (M.H“ulsmann and F.Stryga, 1993 and Dowker et al, 1997) The "Serial Sectioning Technique" (Bramante et al) is another commonly used method. Though this technique allows comparison between instrumented and uninstrumented canals but a complicated set-up is required and physical sectioning of the teeth before preparation can result in unknown tissue changes and loss of material (Bramante et al) CBCT imaging techniques is one of the noninvasive methods for the analysis of canal geometry and efficiency of shaping techniques. According to Ludlow JB et al 2006 and Hatcher, 2010 the CBCT is one of the latest innovations that provide detailed three-dimensional observations at a low radiation dose with higher resolutions leads to increased accuracy and diagnostic capability.

The result of the current study indicates that all three NiTi systems analyzed fell within the allowable taper variability preparation of \pm .05 as per ANSI/ADA specification 101 but there is still a large amount of variation present within the standard regarding files taper preparation.

The results indicate that exhibited taper preparations by three systems are generally different than claimed taper by manufacturer. The largest and statistically significant difference in taper preparation showed in the apical third for all three brands. Protaper Next files prepared higher and in other hand Hyflex CM and Twisted file prepared lower taper than nominal taper .06. In case of remaining part of the canal, except Protaper Next, other two brands showed statistically significant taper preparation variability from claimed taper.

If we consider the overall taper preparation that is from apex to the root canal orifice, the present study indicates that except protaper Next file, 
other two systems showed statistically significant taper preparation variability from nominal taper .06. Lask and co-workers 2006 and Hatch and co-workers 2008 previously compared other rotary NiTi brands demonstrated also taper variability. Zinelis et al reported that none of the files studied complied with nominal size but most were within the ISO limits of tolerance which are also support the observation of present study.

\section{Conclusion}

Within the experimental conditions and results of the present study, it could be concluded that Protaper Next file system is better than Hyflex CM and Twisted files in respect of maintaining the claimed taper, though taper preparation variability present in all three systems. Future studies are required with different diameter size other than size 25. In addition, correlation between correct size gutta percha with tapered endodontic file should also be studied in future.

\section{Acknowledgement:}

We are very much thankful to Mr. Symsundar Mandal, Ph. D.(Statistical Officer, Dept. of Epidemiology \& Biostatistics, Chittaranjan National Cancer Institute, 37, S. P. Mukherjee Road, Kolkata - 700026, India, for his great work as a statistician in this study.

\section{References:}

1. American Dental Association Council on Scientific Affairs, "ANSI/ADA specification no. 101: root canal instruments-general requirements,” 2001

2. C. M. Bramante, A. Berbert, and R. P. Borges, "A methodology for evaluation of root canal instrumentation," Journal of Endodontics, vol. 13, no. 5, pp. 243-245, 1987

3. Cohen's Pathways of the pulp,10th edition,p-233

4. Current Challenges and Concepts of the Thermomechanical Treatment of Nickel-Titanium Instruments-Ya Shen, DDS, PhD, Huimin Zhou, DDS, PhD, Yu-feng Zheng, $\mathrm{PhD}$, Bin Peng, DDS, PhD and Markus Haapasalo, DDS, PhD, JOE - Volume 39, Number 2, February 2013

5. G. J. Dearing, R. B. Kazemi, and R. H. Stevens, "An objective evaluation comparing the physical properties of two brands of stainless steel endodontic hand files," Journal of Endodontics, vol. 31, no. 11, pp. 827-830, 2005

6. G. W. Hatch, S. Roberts, A. P. Joyce, R. Runner, and J. C. McPherson, "Comparative study of the variability of 0.06 tapered 
rotary endodontic files to current taper standards," Journal of Endodontics, vol. 34, no. 4, pp. 463-465, 2008.

7. Hatcher DC. Operational principles for cone-beam computed tomography. J Am Dent Assoc. 2010;141 Suppl 3:3S-6S

8. International Standards Organization (ISO) specification 3630-1, "Dental root-canal instruments: part 1-files, reamers, barbed broaches, rasps, paste carriers, explorers and cotton broaches," 1992

9. J. I. Ingle, "A standardized endodontic technique utilizing newly designed instruments and filling materials,” Oral Surgery, Oral Medicine, Oral Pathology, vol. 14, no. 1, pp. 83-91, 1961

10. J. T. Lask, M. P. Walker, J. C. Kulild, K. P. Cunningham, and P. A. Shull, "Variability of the diameter and taper of size \# 30, 0.04 nickeltitanium rotary files," Journal of Endodontics, vol.32, no. 12, pp. 1171-1173, 2006

11. J. Y. Blum, P. Machtou, C. Ruddle, and J. P. Micallef, “Analysis of mechanical preparations in extracted teeth using ProTaper rotary instruments: value of the safety quotient," Journal of Endodontics, vol. 29, no. 9, pp. 567-575, 2003

12. JB Ludlow, Davies-Ludlow LE, Brooks SL, Howerton WB. Dosimetry of 3 CBCT devices for oral and maxillofacial radiology: CB Mercuray, NewTom 3G and i-CAT. Dentomaxillofac Radiol. 2006;35(4):219-26

13. Lask and co-workers J. T. Lask, M. P. Walker, J. C. Kulild, K. P. Cunningham, and P. A. Shull, "Variability of the diameter and taper of size \# 30, 0.04 nickel-titanium rotary files," Journal of Endodontics, vol. 32, no. 12, pp. 1171-1173 2006

14. M. H"ulsmann and F. Stryga, "Comparison of root canal preparation using different automated devices and hand instrumentation," Journal of Endodontics, vol. 19, no. 3, pp. 141-145, 1993

15. M. Heuer, “The biomechanics of endodontic therapy,” Dental Clinics of North America, vol. 13, pp. 34-59, 1963

16. S. E. P. Dowker, G. R. Davis, and J. C. Elliott, "X-ray microtomography:nondestructive three-dimensional imaging for in vitro endodontic studies," Oral Surgery, Oral Medicine, Oral Pathology, Oral Radiology, and Endodontics, vol. 83, no. 4, pp.510516, 1997

17. S. Zinelis, E. A. Magnissalis, J. Margelos, and T. Lambrianidis, "Clinical relevance of standardization of endodontic files dimensionsaccordingtotheISO3630-1specification,"Journal of Endodontics, vol. 28, no. 5, pp. 367-370, 2002 